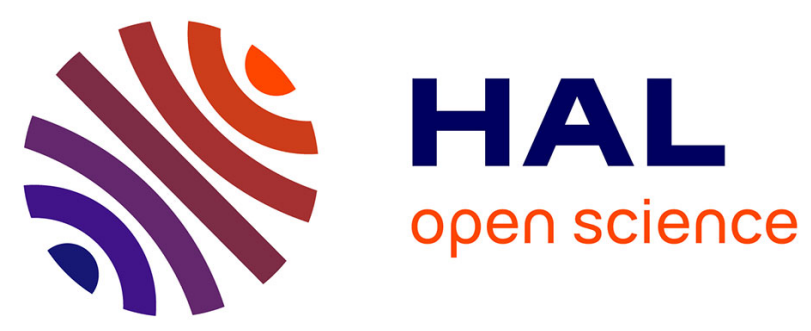

\title{
First report of the tick Hyalomma scupense (natural vector of bovine tropical theileriosis) on the French Mediterranean island of Corsica
}

Sébastien Grech-Angelini, Frédéric Stachurski, Renaud Lancelot, Jérôme Boissier, Jean-François Allienne, Mohamed Gharbi, Gerrit Uilenberg

\section{To cite this version:}

Sébastien Grech-Angelini, Frédéric Stachurski, Renaud Lancelot, Jérôme Boissier, Jean-François Allienne, et al.. First report of the tick Hyalomma scupense (natural vector of bovine tropical theileriosis) on the French Mediterranean island of Corsica. Veterinary Parasitology, 2016, 216, pp.33-37. 10.1016/j.vetpar.2015.11.015 . hal-01259543

\section{HAL Id: hal-01259543 \\ https://hal-sde.archives-ouvertes.fr/hal-01259543}

Submitted on 29 Jan 2021

HAL is a multi-disciplinary open access archive for the deposit and dissemination of scientific research documents, whether they are published or not. The documents may come from teaching and research institutions in France or abroad, or from public or private research centers.
L'archive ouverte pluridisciplinaire HAL, est destinée au dépôt et à la diffusion de documents scientifiques de niveau recherche, publiés ou non, émanant des établissements d'enseignement et de recherche français ou étrangers, des laboratoires publics ou privés. 


\title{
First report of the tick Hyalomma scupense (natural vector of bovine tropical theileriosis) on the French Mediterranean island of Corsica
}

\author{
Sébastien Grech-Angelini ${ }^{\mathrm{a}, *}$, Frédéric Stachurski ${ }^{\mathrm{b}, \mathrm{c},}$, Renaud Lancelot ${ }^{\mathrm{b}, \mathrm{c},}$ Jérôme Boissier ${ }^{\mathrm{d}}$, \\ Jean-François Allienne ${ }^{\mathrm{d}}$, Mohamed Gharbi ${ }^{\mathrm{e}}$, Gerrit Uilenberg ${ }^{\mathrm{f}}$
}

a INRA, UR 045 Laboratoire de Recherches sur le Développement de l'Elevage, Corte, France b CIRAD, UMR CMAEE, 34398 Montpellier, France

c INRA, UMR 1309CMAEE, 34398 Montpellier, France

d Université de Perpignan Via Domitia, IHPE UMR 5244, CNRS, IFREMER, Université de Montpellier, F-66860 Perpignan, France

e Laboratoire de Parasitologie, Ecole Nationale de Médecine Vétérinaire, Université de la Manouba, Sidi Thabet, Tunisia

f "A Surgente", Route du Port, 20130 Cargèse, France

\begin{abstract}
Hyalomma scupense (Acari, Ixodidae) is a common tick species found in several areas in North Africa, Asia and South Europe and an efficient natural vector of bovine tropical theileriosis (Theileria annulata), a livestock disease with an important economic impact. For one year, 1938 ticks were collected on cattle in several Corsican slaughterhouses; 168 of them were morphologically identified as $H$. scupense. This result was confirmed by genetic identification using sequences of mitochondrial cytochrome c oxidase subunit I (COI) and ribosomal internal transcribed spacer 2 (ITS2) genes. The presence of 2 different stages (adults and nymphs), collected in various areas of the island, indicates that a population of $H$. scupense is established in Corsica. However, bovine tropical theileriosis has not been diagnosed on the island so far.
\end{abstract}

\section{KEY WORDS}

Hyalomma scupense ; Cattle ; Molecular identification ; Theileria annulata ; Corsica 


\section{1 - INTRODUCTION}

Hyalomma scupense occurs in a wide area ranging from northernAfrica, Sudan, Turkey, the Middle East, southern Russia and centralAsia, to China; it has also been reported from some southern Euro-pean countries (Apanaskevich et al., 2010). Taxonomic uncertaintyas to the identity of Hyalomma (Euhyalomma) scupense Schulze,1919 and Hyalomma detritum Schulze, 1919 has existed for a longtime, but it is now established that the two names correspond tothe same species; $H$. scupense is the valid name and $H$. detritum is asynonym (Apanaskevich et al., 2010). It is the most abundant ixo-did tick infesting cattle in Morocco and Tunisia (EstradaPena et al.,2004; Gharbi and Darghouth, 2014). This tick species is monotropicand has become endophilic in many regions. H. scupense is a one-or two-host tick; domestic cattle are the most common hostsfor adults and immature stages, but almost all ungulates may beinfested. Single records are also known from other hosts (domes-tic dogs, hares (Lepus sp.), foxes (Vulpes sp.)) and humans areoften attacked by the adults (Hoogstraal, 1956; Apanaskevich et al.,2010). It is one of the most important vectors of bovine tropical theileriosis (Theileria annulata). This protozoan is a major pathogenin the Maghreb region, causing high economic losses in cattle (milkyield decrease, weight loss, abortions, high treatment costs anddeaths; Gharbi et al., 2011). $H$. scupense is also a vector of otherdiseases, including Q-fever (Coxiella burnetii) and equine piroplas-mosis (Theileria equi) (Hoogstraal, 1956). Although H. scupense canprobably transmit the virus of Crimean-Congo hemorrhagic fever(CCHF), it does not appear to be a major vector. Hoogstraal (1979)quoted a study by Chumakov et al. (1973) in which CCHF virusinfection was demonstrated by the fluorescent antibody test inthe salivary glands of $\mathrm{H}$. scupense in Kzyl-Orda Oblast, Kazakhstan.According to Estrada-Pena et al. (2012), H. scupense is one of themain Hyalomma species implicated in the transmission of the virusin Eurasia, but no other evidence of this is given.

Corsica is a French Mediterranean island situated $15 \mathrm{~km}$ northof Sardinia and $90 \mathrm{~km}$ west of Tuscany in Italy (Fig. 1). The island is $183 \mathrm{~km}$ long and $83 \mathrm{~km}$ wide; it is the most mountainous island inthe Mediterranean area (with Monte Cinto peaking at $2706 \mathrm{~m}$ ). Itsclimate is classified as hot summer Mediterranean. About 300,000people live in Corsica and livestock farming is an important eco-nomic activity with approximately 150,000 sheep, 48,000 goats,40,000 pigs and 70,000 cattle. Cattle farming is of a very extensivetype, the animals (mainly local Bos taurus cattle) live outside allyear and usually without any barn.

Neither the tick fauna of Corsica nor the transmitted pathogenshave been fully investigated. However, a few ad hoc studies showedthe existence of three species of the genus Hyalomma on theisland. (i) Hyalomma marginatum is well-established, widespread,and found on many hosts (Morel, 1959; Pérez-Eid, 2007; personal observations). It is one of the main vectors of the zoonotic CCHF virus and an experimental vector of Theileria annulata butunlikely to play a significant role in the field (Estrada-Pena et al.,2004). It is also a vector of Rickettsia spp., including Rickettsia aeschlimanni in Corsica (Matsumoto et al., 2004), and of Babesia caballi, the agent of equine babesiosis (Estrada-Pena et al., 2004). According to Hoogstraal (1956) it is also a natural reservoir of theagent of Q-fever (C. burnetii); (ii) Hyalomma aegyptium is mainlyfound on tortoises although it occasionally infests other hosts, small mammals (hedgehogs, hares, rodents, etc.), lizards and evenbirds (partridges). It has been identified only once in Corsica (onemale) on a tortoise Testudo hermanni (Matsumoto et al., 2004)1;(iii) 
Hyalomma rufipes, a tropical sub-Saharan species, has beencollected on migrating birds and may play a role in the dissemination of $R$. aeschlimanni, with which it has been found infected in Corsica (Matsumoto et al., 2004). This species is known to bethe most important vector of $\mathrm{CCHF}$ virus in southern Africa and italso transmits Anaplasma marginale and Babesia occultans to cattle (Estrada-Pena et al., 2004). Nymphs of this species are commonly found on birds migrating from Africa to Europe (Hoogstraal et al.,1963) and isolated adults have even been reported in Northern Europe.

A better knowledge of the Corsican tick fauna is needed to deter-mine present and potential dangers to human and animal healthrelated to tick-borne pathogens. This was the aim of a systematictick survey carried out in 2014-2015. The finding of the species $H$. scupense during this study is presented here in advance because ofits great potential importance as an efficient vector of T. annulataon cattle.

\section{2 - MATERIALS AND METHODS}

From May 2014 to May 2015, ticks were collected in the 3 Corsican cattle slaughterhouses (Ponte-Leccia, Cuttoli and Porto-Vecchio, Fig. 1), from cattle living in different areas of the island. The national cattle identification system (eartags) allowed to traceback the origin of the cattle. The slaughterhouses of Ponte-Lecciaand Cuttoli were visited monthly, whereas samples were collectedonly three times in Porto-Vecchio. During each visit, the whole skinsof 15-25 cows were examined, just after flaying, and the ticks were manually collected. They were stored in $70 \%$ ethanol at $-20{ }^{\circ} \mathrm{C}$ until their identification according to their morphological characteristics using a stereomicroscope, with the keys and descriptions by Hoogstraal (1956), Walker et al. (2003), Estrada-Pena et al. (2004) and Apanaskevich et al. (2010).

To confirm the morphological identification of $H$. scupense, genomic DNA (gDNA) was extracted and purified from either one ortwo legs, using the QIAamp DNA microkit following manufacturer protocol (Qiagen). The use of only one or two legs allowed both morphological and molecular identification and the remainder of the specimen was kept for examining the presence of pathogenic organisms. Target genomic regions included the mitochondrial cytochrome c oxidase subunit I (COI) genes, as well as the whole sequences of the ribosomal internal transcribed spacer-2 (ITS2) region. The primers used for COI amplification were LCO1490(5_-GGTCAACAAATCATAAAGATATTGG-3_) and HCO2198 (5_TAAACTTCAGGGTGACCAAAAAATCA-3_) (Folmer et al., 1994). The primers used for ITS2 were H1 (5_-TGGCTTCGTCTGTCTGAGGGTC-3_) and H2 (5_TGCTTAAATTCAGCGGGTTGTC-3_). Conventional polymerase chain reaction (PCR) was performed in a total reaction volume of 25 _ L consisting of 2 _L of gDNA, 1X Colourless GoTaqflexi buffer (Promega, Madison, WI, USA), $1.5 \mathrm{mM} \mathrm{MgCl} 2$ (Promega, Madison, WI, USA), $0.2 \mathrm{mM}$ of each dNTP (Promega, Madison, WI,USA, reference U1420), 0.4 _M forward primer, 0.4 _M reverseprimer and 1U GoTaq G2 hotstart Polymerase (Promega, Madison,WI, USA, reference M7405). DNA amplification consisted in anactivation step of $95^{\circ} \mathrm{C}$ for $4 \mathrm{~min}$, followed by 35 cycles of $95^{\circ} \mathrm{C}$ for $40 \mathrm{~s}, 52^{\circ} \mathrm{C}$ for $40 \mathrm{~s}$, and $72^{\circ} \mathrm{C}$ for $1 \mathrm{~min}$ (COI) or 1 min 40 (ITS2), anda final extension at $72{ }^{\circ} \mathrm{C}$ for $5 \mathrm{~min}$. PCR products were visualizedon Labchip GX1 (PerkinElmer). Positive products were sent to Genoscreen (France) for sequencing in both directions using dilutions of the original PCR primers. The sequences were then assembled and manually edited using Sequencher (GeneCodesCorp) to remove any ambiguities between 
strands and sequences. Genetic distance between sequences obtained and reference sequences from GenBank were calculated using Mega V6.0

\section{3 - RESULTS}

A total of 1,938 ticks were collected from cattle, among which168 were identified as $H$. scupense (70 females, 74 males and 24nymphs), representing $8.7 \%$ of the collected ticks (Fig. 2). Ticks were obtained from 72 "communes" (smallest administrative unitin France, Fig. 1) and $H$. scupense were collected from cattle raisedin 21 of them. It represented more than $50 \%$ of the collected ticksin 10 communes. Individuals from this species were collected from December to May, with a peak in January-March, during which H. scupense constituted 40$53 \%$ of the ticks infesting the slaughtered cattle. The 24 nymphs were collected from December to March

Eleven specimens morphologically identified as $H$. scupense (4 males, 4 females and 3 nymphs) were submitted to molecular identification. Ten COI and 8 ITS2 sequences were obtained. Sequence divergence was found within the COI sequences (4 haplotypes; GenBank accession numbers, AN: KT598361, KT598360, KT598362,KT598363). The genetic distance within Corsican specimens was 0.002 (standard deviation of 0.001). No sequence variation was found within ITS sequences (AN: KT598364). All sequences confirm the morphological identification of $H$. scupense. Table 1 showsmean pairwise distance of all the sequences obtained for COI, forITS2 and reference sequences. The genetic distance between the Corsican specimens and $H$. scupense was $0.7 \%$ for both genes while the minimum genetic distance between the Corsican specimens and the other species was $7.7 \%$.

\section{4 - DISCUSSION}

In spite of the large geographic distribution of $H$. scupense inthe world, its presence in Corsica and its relative abundance ( $8.7 \%$ of the collected ticks) were not expected since the species was rarely found in the areas neighboring the island where significant tick studies have been carried out. Two specimens were recorded in Sardinia, on deer (Garippa et al., 2003) and on man (Montarsiet al., 2011); and 7 questing adults (designated as $H$. detritum) were collected on the vegetation on the Tuscan island of Pianosa (Tomassone et al., 2013). It is not frequent in continental Spain (Oteo et al., 2006) and has not been found on Minorca Island (Ros-García et al., 2012). In continental France, the tick was reported inthe South-West where it seems to be established (Macaigne and Pérez-Eid, 1993) though the collected numbers were low. But in Northern Africa where tropical theileriosis is a major cattle disease, H. scupense is often the most widespread tick species on cattle, representing between 84.3 and $99.1 \%$ of the ticks population in Tunisia (in farms affected by tropical theileriosis), $30.8 \%$ in Morocco (Gharbiand Darghouth, 2014) and 13.6\% in Algeria (Benchikh Elfegounet al., 2013). In Corsica, $H$. scupense was reported in almost 30\%of the investigated areas (Fig. 1) and two different stages (adults and nymphs) were found several times on the same animals. These observations provide strong arguments for the existence of an endemic and well-established population of $H$. scupense ticks inCorsica, which is rather surprising for an area of south-western Europe. 
The way H. scupense arrived in Corsica remains unexplained. The role played in the dispersion of ticks by migratory birds has to beconsidered, although this species was so far not found on migrating birds (e.g., Hoogstraal et al., 1963; Wallménius et al., 2014). Cattle are the main hosts of $H$. scupense and although there is currently no introduction of animals from countries where the tick is established to Corsica, this could have happened earlier. As the Corsican tick fauna had never been fully investigated before this study, it cannot be excluded that $H$. scupense may be a long-time established species. A phylogenetic analysis of several $H$. scupense populations, from Corsica but also from Maghreb countries, could perhaps give clues regarding the origin of Corsican ticks.

Although its seasonal dynamics have not been systematically studied as yet, it appears that the habitat and life cycle of $H$. scupense are different in Corsica and in the Maghreb countries, for two reasons. H. scupense is usually described, in the latter regions, as an endophilic tick (Estrada-Pena et al., 2004; Gharbi and Darghouth,2014) with infestations often associated with barns, stables, shedsand pens; because cattle are kept outside in Corsica, the tick can not be endophilic. Secondly, maximum activity of the species was observed from January to March in this study, which is quite different from what Gharbi and Darghouth (2014) described in North Africa with a peak adult activity from May to August.

Theileria buffeli/orientalis, the causative agent of benign theile-riosis, has been reported in Corsica (Uilenberg, 2000) but bovine tropical theileriosis (T. annulata) has not been diagnosed so far. T.annulata is only transstadially transmitted, so the immature $H$. scupense stages cannot be infected before feeding on an infested host.If indeed the Corsican population of $H$. scupense is presently notinfected, migrating birds coming from enzootic areas would notconstitute a risk of introducing $T$. annulata. Such birds have so farnot been found infested by immature $H$. scupense, and moreover, as larvae (and therefore the resulting nymphs) are never infected,the greatest potential danger of $T$. annulata introduction would bethe importation of live carrier cattle from an infected country

The occurrence of $H$. scupense in Corsica highlights however therisk of transmission of $T$. annulata to the local cattle population. Bovine tropical theileriosis occurs in many neighboring Mediter-ranean countries, but has not been reported in continental Italy and Sardinia. It is present in Sicily (Loria et al., 1999), the Spanish Island of Minorca (Ros-García et al., 2012) and continental Spain (García-Sanmartín et al., 2006). In Sicily and continental Spain the main vector of T. annulata is Hyalomma lusitanicum while the vec-tor species is uncertain in Minorca. In the other countries of the Mediterranean area, the main vector appears to be $H$. scupense. Using partial amplification and sequencing of the 18s rRNA gene, Criado-Fornelio et al. (2003) reported the identification of T. annulata in the blood of a bovine animal reared in France. Also Bonnet et al. (2013) detected T. annulata DNA in a single Dermacentor marginatus collected in the field by flagging in southern France (Aveyron). This tick species is not known as a vector of $T$. annulata and finding the pathogen in the tick does not necessarily mean that the tick can transmit it. These two reports certainly need further confirmations and if tropical theileriosis occurred in south-ern France, it would probably have been detected. Because of the extensive livestock management and the rustic local cattle breed, the infection might however remain undetected in Corsica. Bovine tropical theileriosis is one of the most economically important diseases and for the future of eventual improvements on the animal husbandry in Corsica, it is of the utmost importance to determine whether it is present or not on the island 


\section{CONFLICT OF INTEREST}

The authors declare no conflicts of interest.

\section{ACKNOWLEDGMENTS}

We are grateful to the staff of the slaughterhouse of Ponte-Leccia (especially Dr. Sidonie Lefevbre), Cuttoli (especially Magalie Mon-taggioni) and Porto-Vecchio for their help in collecting ticks 


\section{REFERENCES}

Apanaskevich, D.A., Filippova, N.A., Horak, I.G., 2010. The genus Hyalomma Koch,1844. X. Redescription of all parasitic stages of $H$. (Euhyalomma) scupense Schulze, $(=\mathrm{H}$. detritum Schulze) (Acari: Ixodidae) and notes on its biology. FoliaParasitol. 57, 69-78.

Benchikh Elfegoun, M.-C., Gharbi, M., Djebir, S., Kohil, K., 2013. Dynamique d'activité saisonnière des tiques ixodidés parasites des bovins dans deux étages bioclimatiques du nordest algérien. Revue Elev. Méd. Vét. Pays Trop.66, 117-122.

Bonnet, S., de la Fuente, J., Nicollet, P., Liu, X., Madani, N., Blanchard, B., Maingourd, C., Alongi, A., Torina, A., Fernández de Mera, G., Vicente, J., George, J.-C., Vayssier-Taussat, M., Joncour, G., 2013. Prevalence of tick-borne pathogens in adult Dermacentor ticks from nine collection sites in France. Vector-Borne Zoonotic. Dis. 13, 226-236.

Chumakov, M.P., Smirnova, S.E., Shalunova, N.Y., Mart'yanova, L.I., Fleer, G.N., Zgurskaya, G.N., Maksumov, S.S., Kasymov, K.T., Pak, T.P., 1973. Proofs of ecological identity of Crimean hemorrhagic fever and Central Asian hemorrhagic fever. Abstr. Inv. Pap. 9. Int. Congr. Trop. Med. Malar. (Athens),33-54.

Criado-Fornelio, A., Martinez-Marcos, A., Buling-Sarana, A., Barba-Carretero, J.C., 2003. Molecular studies on Babesia, Theileria and Hepatozoon in southern Europe. Part I. Epizootiological aspects. Vet. Parasitol. 113, 189-201.

Estrada-Pena, A., Bouattour, A., Camicas, J.L., Walker, A.R., 2004. Ticks of Domestic Animals in the Mediterranean Region: A Guide to Identification of Species. University of Zaragoza, Zaragoza.

Estrada-Pena, A., Jameson, L., Medlock, J., Vatansever, Z., Tishkova, F., 2012.Unraveling the ecological complexities of tick-associated Crimean-CongoHemorrhagic Fever virus transmission: a gap analysis for the Western Palearctic. Vector-Borne Zoonotic. Dis. 12, 743752.

Foata, J., Mouillot, D., Culioli, J.L., Marchand, B., 2006. Influence of seasonal hostageon wild boar parasites in Corsica using indicator species analysis. J. Helminthol.80, 41-45.

Folmer, O., Black, M., Hoeh, W., Lutz, R., Vrijenhoek, R., 1994. DNA primers for amplification of mitochondrial cytochrome c oxidase subunit I from diverse metazoan invertebrates. Mol. Mar. Biol. Biotech. 3, 294-299.

García-Sanmartín, J., Nagore, D., García-Pérez, A.L., Juste, R.A., Hurtado, A., 2006. Molecular diagnosis of Theileria and Babesia species infecting cattle in Northern Spain using reverse line blot macroarrays. BMC Vet. Res. 2, 16-22.

Garippa, G., Biddau, M., Cherchi, M., 2003. Endo ed ectoparassiti di Cervus elaphus corsicanus della Sardegna. J. Mt. Ecol. 7 (Suppl), 189-190.

Gharbi, M., Darghouth, M.A., 2014. A review of Hyalomma scupense (Acari, Ixodidae) in the Maghreb region: from biology to control. Parasite 21, 2.

Gharbi, M., Touay, A., Khayeche, M., Laarif, J., Jedidi, M., Sassi, L., Dhargouth, M.A., 2011. Ranking control options for tropical theileriosis in at-risk dairy cattle inTunisia: using benefit-cost analysis. Rev. Sci. Tech. Off. Int. Epiz. 30, 763-778.

Hoogstraal, H., 1956. African Ixodoidea. Volume I. Ticks of the Sudan. Research Report NM, Cairo, Egypt, 1101 pp.

Hoogstraal, H., 1979. The epidemiology of tick-borne Crimean-Congo hemorrhagic fever in Asia, Europe and Africa. J. Med. Entomol. 15, 307-417. 
Hoogstraal, H., Kaiser, M.N., Traylor, M.A., Gaber, S., Guindy, E., 1963. Ticks (Ixodoidea) on birds migrating from Africa to Europe and Asia 1959-61. Bull.World Health Organ. 24, 197-212.

Loria, G.R., Riili, S., Vitale, F., Greco, A., Sparagano, O., 1999. Clinical and laboratory studies on theileriosis outbreaks in Sicily, Italy. Parassitologia 41 (Suppl. 1),63-67.

Macaigne, F., Pérez-Eid, C., 1993. Hyalomma scupense Schulze 1919 (Acarina, Ixodoidea) tique autochtone du sud-ouest de la France. Ann. Parasitol. Hum.Comp. 68, 199-200.

Matsumoto, K., Parola, P., Brouqui, P., Raoult, D., 2004. Rickettsia aeschlimanni in Hyalomma ticks from Corsica. Eur. J. Clin. Microbiol. Infect. Dis. 23, 732-734.

Montarsi, F., Maioli, G., Fois, F., Mereu Piras, P., Magliano, A., Pascucci, I., Toma, L., Mignone, W., Torina, A., Capelli, G., 2011. Uncommon ticks from Italy. In:Proceeding of the 7th International Conference Ticks and Tick-borne Pathogens (TTP7), Zaragoza, p. 213.

Morel, P.-C., 1959. Les Hyalomma (Acariens: Ixodidae) de France. Ann. Parasitol.Hum. Comp. 34, 552-555.

Oteo, J.-A., Portillo, A., Santiba nez, S., Perez-Martinez, L., Blanco, J.-R., Jimenez, S., Ibarra, V., Pérez-Palacios, A., Sanz, M., 2006. Prevalence of spotted fever group Rickettsia species detected in ticks in La Rioja, Spain. Ann. N. Y. Acad. Sci. 1078,320-323.

Pérez-Eid, C., 2007. Les tiques. Identification, biologie, importance médicale et vétérinaire. Lavoisier, Editions TEC\&DOC, 2007, 314 pp.

Ros-García, A., García-Pérez, A.L., Verdera, J., Juste, R.A., Hurtado, A., 2012.Monitoring piroplasms infection in three cattle farms in Minorca (Balearic Islands, Spain) with previous history of clinical piroplasmosis. Vet. Parasitol.190, 318-325.

Tomassone, L., Grego, E., Auricchio, D., Iori, A., Gianni, F., Rambozzi, 2013. Lyme borreliosis spirochetes and spotted fever group rickettsiae in ixodid ticks from Pianosa Island, Tuscany Archipelago, Italy. Vector-Borne Zoonotic. Dis. 13,84-91.

Uilenberg, G., 2000. Tick-borne infections of cattle on Corsica. ICTTD newsletter n॰14, 2000, 13 (ISSN: 1385-3422).

Walker, A.R., Bouattour, A., Camicas, J.-L., Estrada-Pena, A., Horak, I.G., Latif, A.A., Pegram, R.G., Preston, P.M., 2003. Ticks of Domestic Animals in Africa. A Guide to Identification of Species. Bioscience Reports, Edinburgh, Scotland, UK221.

Wallménius, K., Barboutis, C., Fransson, T., Jaenson, T.G., Lindgren, P.-E., Nyström,F., Olsen, B., Salaneck, E., Nilsson, K., 2014. Spotted fever Rickettsia species in Hyalomma and Ixodes ticks infesting migratory birds in the European Mediterranean area. Parasit. Vectors 7, 318. 


\section{FIGURE 1}

Localization of Hyalomma scupense and proportion of this species among the ticks collected on cattle in Corsica
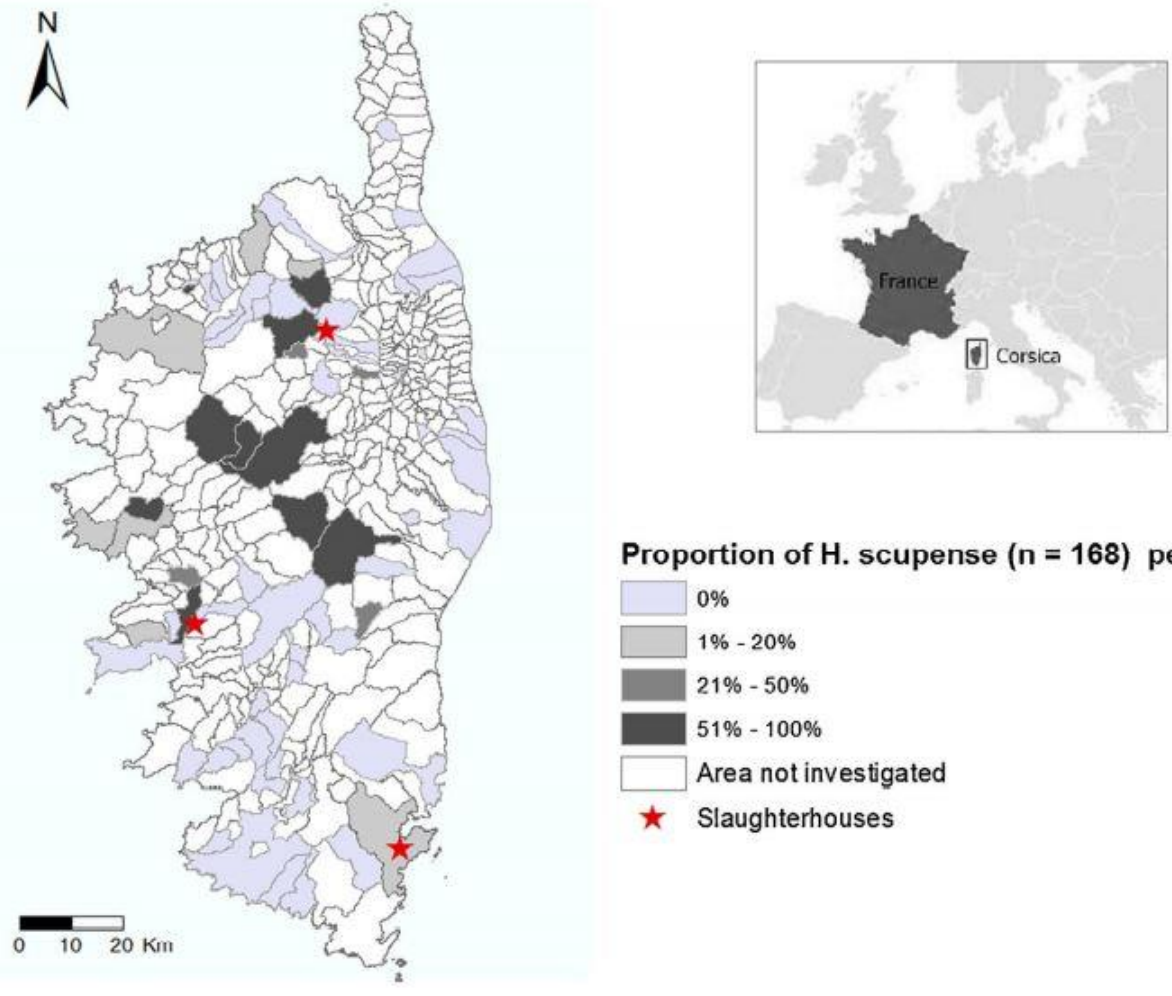

Proportion of $H$. scupense $(n=168)$ per commune

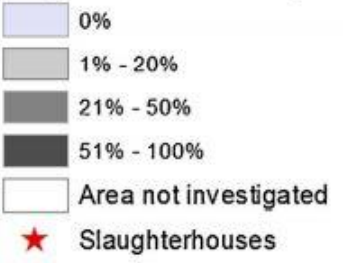




\section{FIGURE 2}

Dorsal view of a male of Corsican Hyalomma scupense

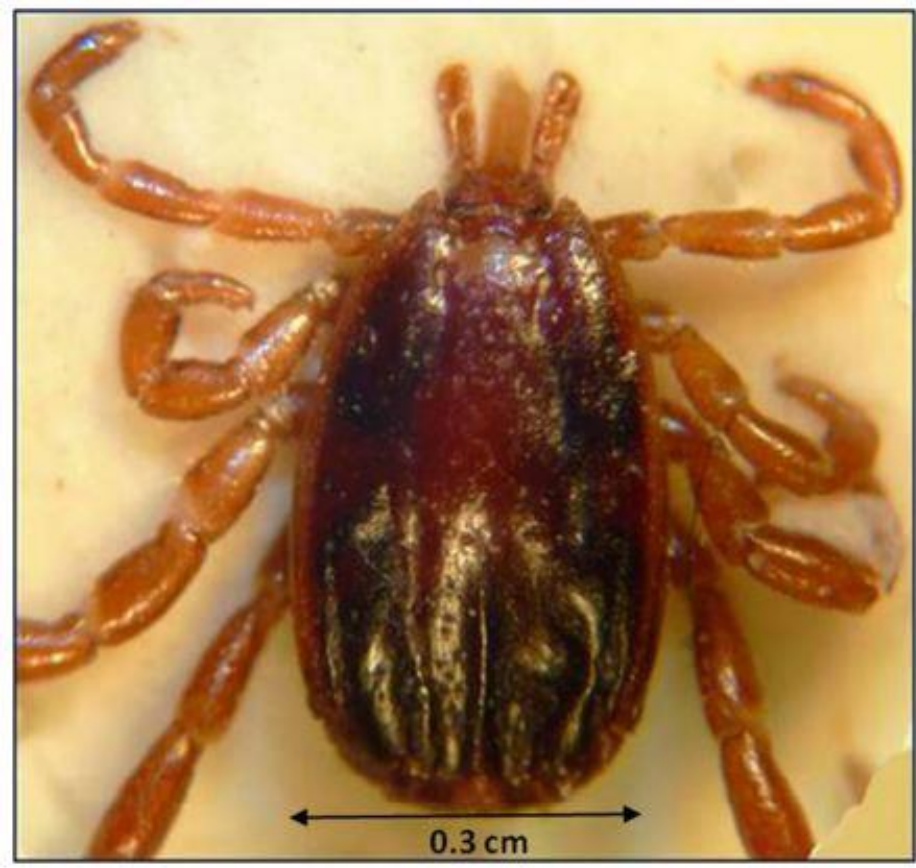




\section{TABLE 1}

Pair-wise genetic distances between COI and ITS2 of reference sequences and Corsican specimens (accesssion numbers are between parentheses)

\begin{tabular}{|c|c|c|c|c|c|c|c|}
\hline & $\mathrm{COI}$ & 1 & 2 & 3 & 4 & 5 & 6 \\
\hline 1. & H. dromedarii (AJ437083) & & & & & & \\
\hline 2. & H. anatolicum (KF912622.2) & $8.7 \%$ & & & & & \\
\hline 3. & H. asiaticum (KF527440.1) & $14.7 \%$ & $16.9 \%$ & & & & \\
\hline 4. & H. lusitanicum (EU827743) & $9.6 \%$ & $9.3 \%$ & $15.5 \%$ & & & \\
\hline 5. & H. marginatum (EU827693.1) & $4.0 \%$ & $8.7 \%$ & $14.6 \%$ & $8.2 \%$ & & \\
\hline 6. & H. scupense (KM235712.1) & $12.6 \%$ & $15.2 \%$ & $9.8 \%$ & $13.6 \%$ & $11.7 \%$ & \\
\hline \multirow[t]{2}{*}{7.} & Corsican specimens $(n=10)$ & $13.3 \%$ & $15.3 \%$ & $10.9 \%$ & $14.7 \%$ & $13.3 \%$ & $0.7 \%$ \\
\hline & ITS2 & & 1 & 2 & & 3 & 4 \\
\hline 1. & H. asiaticum (JX845148) & & & & & & \\
\hline 2. & H. anotalicum (HQ005303) & & $11.1 \%$ & & & & \\
\hline 3. & H. marginatum (JQ737104) & & $11.1 \%$ & $4.6 \%$ & & & \\
\hline 4. & H. scupense (JX845150) & & $8.6 \%$ & $8.3 \%$ & & $8.3 \%$ & \\
\hline 5. & Corsican specimens $(n=8)$ & & $7.8 \%$ & $7.6 \%$ & & $7.7 \%$ & $0.7 \%$ \\
\hline
\end{tabular}

